\title{
DYNAMIC LOGIC WITH POSSIBLE WORLD
}

\author{
Ruzhan I.u \\ Department of Computer Science and Hingineering \\ Shanghai Jiao 'Tong University, Shanghai 200030, P. R. China
}

\begin{abstract}
This paper introduces a semantic theory DI.PW, Dynamic Iogic with Possible World, which extends Groenendijk's IDPI, and Cresswoll's Indices Semantics. The semantics can interpret the temporal and modal sense and anaphora.
\end{abstract}

Key words: Semantic Model, Dynamic Logic, Possible Worlds.

\section{$\S 1$ Introduction}

At present there are three main aspects in semantical field:

1. Transformation of sentences or discourses into formulas in high order logic.

2. Semantic interpretation of the logical formulas.

3. Semantic ambiguity.

'This paper presents the semantics, dynamic logic with possible world, which combines DPI ${ }^{[3]}$ with Indices semantics ${ }^{[1]}$ and extends the theories, the theory can be used to interpret the temporal and modal sense and anaphoric connection. For the limitation of space we only give the defi. nitions and examples concerned rather than present a formalization which should include the axioms and rules concerned like in DPI, ${ }^{[3]}$.

Following Montague semantics, the discussion on meaning of a sentence started with predicate formula, high order logical formual with lambda terms, which is translated from a sentence $\mathrm{S}$ by means of a set of rules and reduced to a first order predicate formula $A$ finally.

Problem : given an expression $\Lambda$, meani$\mathrm{ng}[\Lambda]=$ ? Assume that a model $M$ is an ordered pair $\langle D, F\rangle$ where $D$ is a domain, a non-empty set and $F$ an interpretation function assigning a semantic value to each non-logical constant of the language. $\Lambda$ value assignment $\mathrm{g}$ is a function assigning a member of D to each variable of the language. $\mathrm{W}$ is a possible world. The intension of the expression $A$ is $\operatorname{Int}[\Lambda]=$ $\|A\|^{M, r}$. The extension of the expression $\Lambda$ is $\operatorname{Fxt}[\Lambda, W]=\operatorname{Int}[A](W)=\|\Lambda\|^{M, W, z}$.

Some semantic evaluations are as follows :

1. Montague Semantics, given $M, W$, evaluates extension $\|\Lambda\|^{M, W, g}$.

2. Possible World Semantics (M. J. Cresswell), given $M, W$, finds the set of possible worlds which satisfy the extension of A. i.e., $\left\{W \mid\|A\|^{M, W},=\right.$ 'T'rue $\}$.

3. Dynamic Predicate Logic (J. Groenendi$\mathrm{jk}$ ), given $M, W$, finds dynamic changes between the value assignments:

$$
\|A\|^{M, w}=\left\{\left\langle g_{\text {in }}, g_{\text {out }}\right\rangle\right\} \text {. }
$$

4. Dynamic Logic with Possible World, given $\mathrm{M}$, finds dynamic changes between the ordered pairs of value assignment and world: $\|A\|^{M}:\left\{\left\langle G_{\text {in }}, G_{\text {nut }}\right\rangle \mid G_{\text {in }}=\left\langle g_{\text {in }}, W_{\text {in }}\right\rangle\right.$, $\left.G_{\text {out }}=\left\langle g_{\text {out }}, W_{\text {out }}\right\rangle\right\}$.

The evaluations 1,2 above are in static sense and for use of interpretation of sentences without anaphora, while evalu- 
ations 3,4 above in dynamic sense and for use of interpretation of anaphoric connection.

\section{$\S 2$ DLPW, Anaphoric Connection}

In this section we hope that DLPW can offer a successful application to anaphoric connection like the intepretation of the famous donkey sentence in Groenendijk's $\mathrm{DPL}^{[3]}$. The sentence

(1) There was a key, it is lost. can be formalized as

(2) $\mathrm{P} \exists_{x} \operatorname{key}(\mathrm{x})$ \& NOW $\operatorname{lost}(\mathrm{x})$ (in the hope that) having the same semantic interpretation as the formula

(3) $\mathrm{P} \exists_{x}(\operatorname{key}(\mathrm{x}) \& \mathrm{NOW} \operatorname{lost}(\mathrm{x}))$.

The idea will come true by means of dynamic logic DLPW. A state, denoted by $\pi$ $(=\langle\sigma, g\rangle)$, may be a pair of a sequence of time $\sigma(\sigma=\{\sigma(0), \sigma(1)\})$ and a value assign. ment $\mathrm{g}$.

There are revisions of semantic definitons of operators concerned.

(4) $\|$ NOW $\alpha \|=\left\{\left\langle\pi_{1}, \pi_{2}\right\rangle \mid \pi_{1}=\left\langle\sigma_{1}, g_{1}\right\rangle\right.$, $\left.\pi_{2}=\left\langle\sigma_{2}, \mathrm{~g}_{2}\right\rangle,\left\langle\left\langle\sigma_{1}[1 / 0], \mathrm{g}_{1}\right\rangle, \pi_{2}\right\rangle \in\|\alpha\|\right\}$.

(5) $\|\mathrm{P} \alpha\|=\left\{\left\langle\pi_{1}, \pi_{2}\right\rangle \mid \pi_{1}=\left\langle\sigma_{1}, \mathrm{~g}_{1}\right\rangle\right.$, $\pi_{2}=\left\langle\sigma_{2}, \mathrm{~g}_{2}\right\rangle, \exists_{t}\left(\mathrm{t}<\sigma_{1}(0)\right.$, $\left\langle\left\langle\sigma_{1}[\right.\right.$ term $\left.\left.\left.\left.t / 0], g_{1}\right\rangle, \pi_{2}\right\rangle \in\|\alpha\|\right)\right\}$.

(6) $\|\varphi \& \psi\|=\left\{\left\langle\pi_{1}, \pi_{2}\right\rangle \mid \exists_{\pi, \pi^{\prime}}(\pi=\langle\sigma, \mathrm{g}\rangle\right.$, $\pi^{\prime}=\left\langle\sigma^{\prime}, \mathbf{g}\right\rangle,\left\langle\pi_{1}, \pi\right\rangle \in\|\varphi\|$, $\left.\left.\left\langle\pi^{\prime}, \pi_{2}\right\rangle \in\|\psi\|\right)\right\}$.

(7) $\left\|\exists_{x} \varphi\right\|=\left\{\left\langle\pi_{1}, \pi_{2}\right\rangle \mid \exists{ }_{\pi}\right.$, $\left.\left(\pi=\langle\sigma, \mathrm{g}\rangle, \mathrm{g}=\mathrm{g}_{1}[\mathrm{x}],\left\langle\pi, \pi_{2}\right\rangle \in\|\varphi\|\right)\right\}$.

(8) $\|\varphi(\mathrm{x})\|=\left\{\left\langle\pi_{1}, \pi_{2}\right\rangle \mid \pi_{1}=\pi_{2}\right.$, $\left.\mathrm{g}_{1}=\mathrm{g}_{2}, \mathrm{~g}_{1}(\mathrm{x}) \in \mathrm{F}(\varphi)\right\}$.

Where $F(\varphi)$ is a set of individuals, $F$ is the function in a model M. $\varphi$ is an atomic formula. Here obviously, conjunction is treated like composition ( i.e., compound statement $\left.\left\{\mathrm{S}_{\psi} ; \mathrm{S}_{\psi}\right\}\right)$. Intuitively, the conjunction is treated in the sequential sense. The meanings of the formulas $\sigma_{1}[1 / 0]$, $\sigma_{1}[$ term $t / 0], \mathrm{g}_{1}[\mathrm{x}]$ follow the statements in the preceding section.

Assume that initially for all i, j, $\sigma_{i}(\mathrm{j})=\mathrm{t}_{0}$ and $\sigma_{i}, \mathrm{~g}_{i}$ in $\pi_{i}$ denoted components concerned. Hence

(9) $\left\langle\pi_{1}, \pi_{2}\right\rangle \in\|(2)\|$ iff, by (6), for some $\pi_{3}, \pi_{3}{ }^{\prime}, \mathrm{g}_{3}\left(=\mathrm{g}^{\prime}{ }^{\prime}\right)$,

(10) $\left\langle\pi_{1}, \pi_{3}\right\rangle \in\left\|P \exists_{x} \operatorname{key}(\mathrm{x})\right\|$ and

(1.1) $\left\langle\pi_{3}{ }^{\prime}, \pi_{2}\right\rangle \in \|$ NOW $\operatorname{lost}(\mathrm{x}) \|$. (10) holds iff, by (5), for some $\mathrm{t}\left(<\sigma_{1}(0)\right)$,

(12) $\left\langle\left\langle\sigma_{1}[\right.\right.$ term $\left.\left.t / 0], g_{1}\right\rangle, \pi_{3}\right\rangle \in$ $\left\|\exists_{x} \operatorname{key}(\mathrm{x})\right\|$ iff, by (7), for some $h\left(=\mathrm{g}_{1}[\mathrm{x}]\right)$,

(1.3) $\left\langle\left\langle\sigma_{1}\left[\right.\right.\right.$ term t/0], $\left.\left.g_{1}[x]\right\rangle, n_{3}\right\rangle \in$ $\|$ key $(\mathrm{x}) \|$ iff, by (8),

(14) $\pi_{3}=\left\langle\sigma_{1}[\right.$ term $\left.\mathrm{t} / 0], \quad \mathrm{g}_{1}[\mathrm{x}]\right\rangle$ (i.e. $\sigma_{3}$

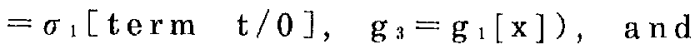
$g_{1}[x](x) \in F\left(\right.$ key), where $g_{1}[x](x)=h(x)$.

(11) holds, iff, by (4),

(15) $\left\langle\left\langle\sigma_{3}{ }^{\prime}[1 / 0], \mathrm{g}^{\prime}{ }^{\prime}\right\rangle, \pi_{2}\right\rangle \in\|\operatorname{lost}(\mathrm{x})\|$, iff by (8), $\left.\pi_{2}=\sigma_{3}{ }^{\prime}[1 / 0], \mathrm{g}_{3}{ }^{\prime}\right\rangle$ (i.e., $\sigma_{2}=\sigma_{3}{ }^{\prime}[1 / 0]$ and $\mathrm{g}_{2}=\mathrm{g}_{3}{ }^{\prime}=\mathrm{g}_{3}$, (by $\left.(6)\right)=\mathrm{g}_{1}[\mathrm{x}]$ (by (14)), and $g_{3}(x) \in F($ lost).

It means that $\mathrm{g}_{3}(\mathrm{x})\left(=\mathrm{g}_{1}[\mathrm{x}](\mathrm{x})=\right.$ individual $k_{n}$, say) is a key at $t\left(<t_{0}\right)$ and $g_{3}(x)$ $\left(=k_{0}\right)$ is lost at $t_{0}$.

On the other hand, for the formula (3),

(16) $\left\langle\pi_{1}, \pi_{3}\right\rangle \in\|(3)\|$ iff, by (5), for some $\mathrm{t}\left(<\sigma_{1}(0)\right)$,

(17) $\left\langle\left\langle\sigma_{1}[\right.\right.$ term t $\left.\left./ 0], \mathrm{g}_{1}\right\rangle, \pi_{2}\right\rangle \in$ $\| \exists_{x}(\operatorname{key}(\mathrm{x})$ \& NOW $\operatorname{lost}(\mathrm{x})) \|$, iff, by (6) for some $\mathrm{h}\left(=\mathrm{g}_{1}[\mathrm{x}]\right)$,

(18) $\left\langle\left\langle\sigma_{1}\left[\right.\right.\right.$ term t/0], $\left.\left.\mathrm{g}_{1}[\mathrm{x}]\right\rangle, \pi_{2}\right\rangle \in$ $\|$ key $(x)$ \& NOW $\operatorname{lost}(x) \|$, iff, by (6) for some $\pi_{3}, \pi_{3}{ }^{\prime}, \mathrm{g}_{3}\left(=\mathrm{g}_{3}{ }^{\prime}\right)$,

(19) $\left\langle\left\langle\sigma_{1}[\text { term t } / 0], \mathrm{g}_{1}[\mathrm{x}]\right\rangle, \pi_{3}\right\rangle_{E}$

$\|\operatorname{key}(\mathrm{x})\|$ and

(20) $\left\langle\pi_{3}{ }^{\prime}, \pi_{2}\right\rangle \in\|N O W \operatorname{lost}(\mathrm{x})\|$, (19) holds iff $\pi_{3}=\left\langle\sigma_{1}[\right.$ term $t / 0]$, $\left.g_{1}[x]\right)$, and $g_{1}[x](x) \in F(k e y)$, i.e., $\sigma_{3}=\sigma_{1}[$ term $\mathrm{t} / 0]$ and $\mathrm{g}_{3}=\mathrm{g}_{1}[\mathrm{x}]$,

(20) holds iff, by (4),

(21) $\left\langle\left\langle\sigma_{3}{ }^{\prime}[1 / 0], \mathrm{g}_{3}{ }^{\prime}\right\rangle, \pi_{2}\right\rangle \in\|\operatorname{lost}(\mathrm{x})\|$ iff, 
by $(8), \pi_{2}=\left\langle\sigma_{3}{ }^{\prime}[1 / 0], \mathrm{g}_{3}{ }^{\prime}\right\rangle$, and $\mathrm{g}_{3}{ }^{\prime}(\mathrm{x}) \in$

$\mathrm{F}($ lost $)$, i.c., $\sigma_{2}=\sigma_{3}{ }^{\prime}[1 / 0]$ and $\mathrm{g}_{2}=\mathrm{g}_{3}{ }^{\prime}=$ $\mathrm{g}_{3}=\mathrm{g}_{1}[\mathrm{x}]$.

It shows formulas (2) and (3) have identical meaning. This is just what we require.

\section{Acknowledgement}

'The research work is supported in part by the National Natural Science Foundation and The National Key Tab. of Computer Software New Technology in Nanking University.

\section{Reference}

[1] Cresswell. M. J. Lntities and Indices, Kluwer Academic Publishers, 1990.

[2] Dowty. D. R. Introduction to Montague Semantics. D. Reidel. 1981.

[3] Groenendijk. J. S. Dynamic Predicate Logic, Linguistic and Philosophy, Vol.14. No.1, 1991.

[4] Ruzhan Lu. About Semantic Theory and Understanding Natural Language, TU Berlin, Tech. Report. 1992.

[5] Ruzhan Lu. Dynamic Semantic with Indices, TU Berlin, 'I'ech. Report. 1992. 